\title{
Aplikasi Navigasi Berbasis Perangkat Bergerak dengan Menggunakan Platform Wikitude untuk Studi Kasus Lingkungan ITS
}

\author{
Imaduddin Al Fikri, Darlis Herumurti, dan Ridho Rahman H. \\ Jurusan Teknik Informatika, Fakultas Teknologi Informasi, Institut Teknologi Sepuluh Nopember \\ (ITS) \\ Jl. Arief Rahman Hakim, Surabaya 60111 Indonesia \\ e-mail: ridho@if.its.ac.id ${ }^{3)}$
}

\begin{abstract}
Abstrak- Bagi setiap orang yang baru mengunjungi ITS, sebagian besar akan kesulitan mencari tempat yang ada di ITS. Dengan bantuan rambu-rambu yang ada di ITS dan aplikasi maps yang sekarang ada, masih belum menyelesaikan permasalahan. Oleh karena itu, perlu dibuat sebuah aplikasi yang lebih dapat membantu pengunjung untuk menemukan tempat di ITS. Salah satu teknologi yang sedang berkembang saat ini adalah teknologi augmented reality. Augmented reality merupakan teknologi di mana memungkinkan pengguna untuk berinteraksi dengan objek dunia maya yang diproyeksikan pada dunia nyata. Aplikasi yang akan dibangun dapat menunjukkan rute dan tempat yang akan dituju dalam tampilan augmented reality. Google Maps API digunakan untuk mencari rute terdekat antar dua tempat. Untuk mengembangkan tampilan augmented reality, digunakan Wikitude Android SDK. Hasil pengujian aplikasi menunjukkan bahwa aplikasi ini dapat menampilkan navigasi dengan tampilan augmented reality sehingga penanda bantu navigasi seakan-akan ada di dunia nyata. Dapat ditarik kesimpulan bahwa aplikasi ini dapat lebih membantu pengguna dalam menemukan tempat yang ingin dituju.
\end{abstract}

Kata Kunci-Augmented Reality, ITS, Location Based Service, Navigasi, Perangkat Bergerak, dan Wikitude.

\section{PENDAHULUAN}

I NSTITUT Teknologi Sepuluh Nopember menempati areal seluas 180 hektar dan memiliki luas bangunan kurang lebih $150.000 \mathrm{~m} 2$. Bagi setiap orang yang baru mengunjungi ITS sebagian besar akan kesulitan untuk mencari lokasi dari tempat yang ingin dituju di ITS, misalnya ingin mengunjungi sebuah jurusan tertentu. Solusi sementara yang tersedia untuk sekarang ini adalah peta ITS dan juga adanya tanda-tanda penunjuk ke arah tertentu yang banyak ditemui di jalanan di dalam ITS.

Saat ini, sudah ada teknologi GPS yang digabungkan dengan aplikasi Maps yang ada dan digunakan sebagai alat navigasi. Aplikasi Maps yang ada masih berbasis peta dua dimensi (2D). Di lain teknologi, untuk membawa objek virtual ke dalam dunia nyata, sekarang sudah ada teknologi Augmented Reality. Dengan adanya teknologi ini, kita dapat mengintegrasikan kondisi di dunia nyata dengan dunia virtual sesuai dengan yang kita inginkan. Teknologi tersebut juga berkembang dengan munculnya Location Based Augmented Reality yaitu peletakan objek virtual sesuai dengan posisi yang kita inginkan di dunia nyata berdasarkan informasi latitude dan longitude.

Dengan adanya permasalahan dan teknologi yang sedang berkembang, usulan tugas akhir ini adalah membuat suatu aplikasi navigasi pada perangkat bergerak dengan mengaplikasikan teknologi Location Based Augmented Reality.

Dengan aplikasi tersebut, diharapkan lebih memudahkan orang yang baru mengunjungi ITS untuk mengunjungi lokasi yang ingin dituju yang berada dalam lingkungan ITS.

\section{TINJAUAN PUSTAKA}

\section{A. Augmented Reality}

.Augmented Reality merupakan sebuah teknologi yang menambahkan informasi-informasi dari komputer ke dalam dunia nyata. Informasi tersebut dapat berupa tulisan, gambar, video, dan lain sebagainya [1]. Informasi tersebut dapat dimunculkan melalui deteksi yang berbeda-beda, antara lain deteksi gambar, bidang, dan lokasi.

\section{B. Location Based Service}

Location Based Service merupakan sebuah layanan yang menyediakan informasi dengan menggunakan informasiinformasi geografis yang ada pada sebuah perangkat [2]. Salah satu contoh aplikasi yang memakai konsep ini adalah aplikasi Maps.

\section{Android Studio}

Android Studio merupakan sebuah Integrated Development Environment (IDE) khusus untuk membangun aplikasi yang berjalan pada platform android. Android studio ini berbasis pada IntelliJ IDEA [3], sebuah IDE untuk bahasa pemrograman Java. Bahasa pemrograman utama yang digunakan adalah Java, sedangkan untuk membuat tampilan atau layout, digunakan bahasa XML. Android studio juga terintegrasi dengan Android Software Development Kit (SDK) untuk deploy ke perangkat android [3].

\section{GPS}

GPS merupakan singkatan dari Global Positioning System yang merupakan sistem navigasi yang dapat memberikan informasi tentang sebuah lokasi. GPS merupakan teknologi yang awalnya digunakan untuk kepentingan militer dan 
sekarang dapat digunakan untuk kepentingan masyarakat biasa [4].

\section{E. Google Maps API}

Google Maps API adalah salah satu Application Programming Interface (API) yang dimiliki Google. API ini mempunyai fitur untuk melakukan aktivitas-aktivias yang berkaitan dengan Google Maps, antara lain menampilkan peta, mencari rute terdekat antara dua tempat, dan lain sebagainya [5]. Google Maps API tersedia untuk platform android, iOS, web, dan juga web service [5].

Dalam pengerjaan aplikasi ini, digunakan dua macam API, yaitu Google Maps Android API untuk menampilkan peta pada layout android serta menangani interaksi dengan peta pada android dan Google Maps Javascript API untuk melakukan request rute terpendek ke server milik Google berupa http request dengan format url sebagai berikut " https://maps.googleapis.com/maps/api/directions/ + params."

Return value dari Google Maps Javascript API berupa string dengan format JSON yang berisi koordinat awal dan tujuan, rute, dan manuver.

\section{F. Wikitude SDK}

Wikitude SDK merupakan sebuah library yang digunakan untuk membangun aplikasi Augmented Reality. Wikitude SDK berisi library untuk location based augmented reality, image recognition, dan image tracking [6]. Wikitude menyediakan berbagai macam API untuk mengembangkan aplikasi augmented reality ke beberapa platform. API yang disediakan antara lain [6] :

- Perangkat bergerak

- Ekstensi

- Kacamata pintar

- Cloud services

Pada pengerjaan aplikasi ini akan digunakan Android SDK versi javascript dikarenakan untuk SDK native masih belum support dengan location based service. Arsitektur dari Wikitude SDK dapat dilihat pada Gambar 1. Pada arsitektur dijelaskan bahwa Wikitude SDK terbagi menjadi tiga lapisan, yaitu : lapisan Computer Vision Engine yang merupakan engine utama dari Wikitude SDK, lapisan API yang menghubungkan engine utama dengan aplikasi atau platform yang ingin dibangun, dan terakhir adalah lapisan aplikasi.

\section{Wikitude SDK Architecture (5.0)}

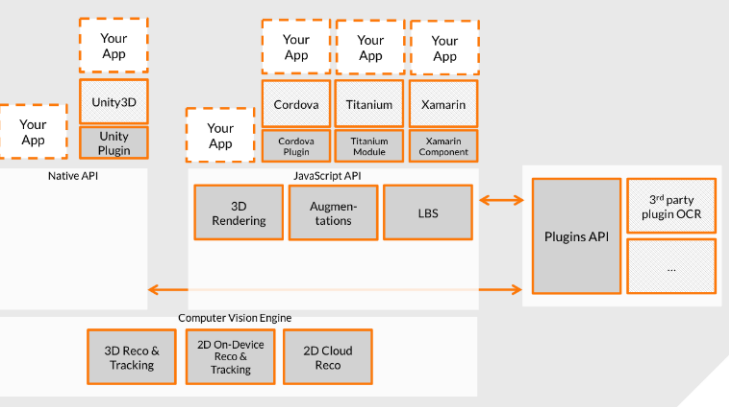

Gambar. 1. Arsitektur Wikitude SDK.

\section{ANALISIS DAN PERANCANGAN}

\section{A. Analisis Permasalahan}

Sulitnya orang yang baru mengunjungi ITS dalam mencari lokasi-lokasi di ITS. Hal ini dikarenakan ITS memiliki area yang cukup luas yaitu sekitar 180 hektar dan memiliki luas bangunan yaitu kurang lebih $150.000 \mathrm{~m}^{2}$ [7]. Penunjuk jalan dan aplikasi navigasi yang ada belum sepenuhnya membantu untuk menemukan lokasi yang ada di ITS.

Permasalahan utama yang diangkat pada penelitian ini adalah bagaimana membangun aplikasi yang menggabungkan teknologi Augmented Reality dan Location Based Service dengan menggunakan Wikitude SDK. Pengguna dapat melihat daftar tempat yang ada di ITS lalu mencari rute terdekat dari tempat tersebut dari posisinya sekarang. Diharapkan dengan dibangunnya aplikasi ini dapat menjadi solusi dari permasalahan di atas.

\section{B. Analisis Sistem}

Aplikasi yang akan dibangun merupakan aplikasi berbasis perangkat bergerak dan sebuah aplikasi berbasis web. Aplikasi bebasis web merupakan webservice yang digunakan untuk melakukan manajemen data lokasi yang ada di ITS. Webservice ini berisi data nama lokasi dan juga koordinat dari lokasi tersebut. Sedangkan aplikasi berbasis perangkat bergerak merupakan aplikasi navigasi yang dapat menampilkan visualisasi rute dalam tampilan peta dua dimensi dan juga dalam tampilan Augmented Reality.

Kebutuhan utama dalam aplikasi ini antara lain :

1. pengguna dapat memilih destinasi yang ingin dituju di ITS,

2. pengguna dapat melihat peta yang di dalamnya terdapat rute terpendek yang harus ditempuh mengguna untuk menuju destinasi,

3. pengguna dapat melihat navigasi yang divisualisasikan dalam tampilan Augmented Reality.

\section{Perancangan Sistem}

Perancangan sistem ini tergambar pada Gambar 2 mengenai arsitektur dari sistem. Aplikasi berbasis web berguna untuk memanajemen data lokasi yang ada di ITS. Data yang disimpan adalah nama lokasi dan koordinat lokasi. Aplikasi berbasis web akan diletakkan pada server shared hosting. Disediakan API agar aplikasi berbasis perangkat bergerak dapat mengakses data ini. API ini dapat diakses dengan melakukan http request dengan format yang sudah ditentukan dan mengembalikan string dengan format JSON yang berisi data lokasi. Data lokasi dari API digunakan aplikasi berbasis perangkat bergerak untuk menampilkan dan menentukan lokasi tujuan. Sementara aplikasi berbasis aplikasi perangkat bergerak menentukan posisi pengguna dengan mendapatkan koordinat dari GPS perangkat bergerak milik pengguna. Untuk menampilkan peta dua dimensi, digunakan Google Maps Android API. Sedangkan untuk mencari rute terdekat, digunakan Google Maps Javascript API. 


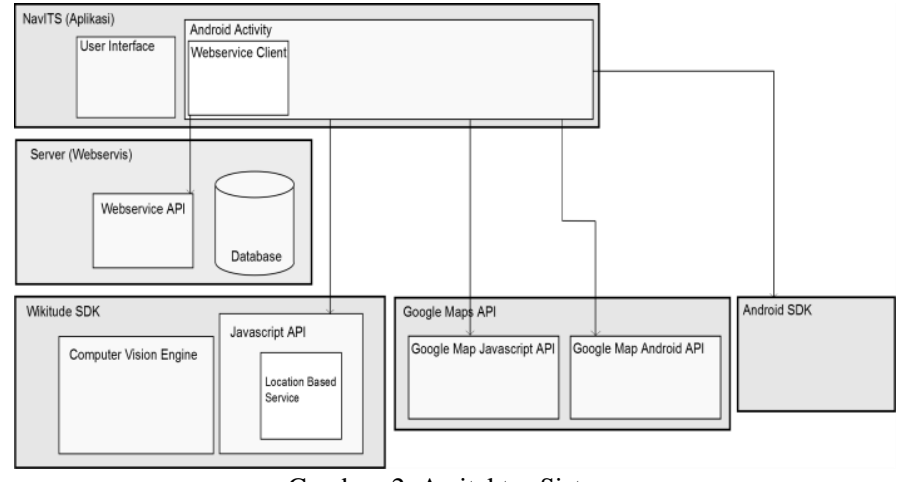

Gambar. 2. Arsitektur Sistem

\section{Perancangan Proses dan Alur Penggunaan Aplikasi}

Proses yang dibangun pada aplikasi ini adalah proses mendapatkan daftar lokasi yang ada di ITS, proses deteksi lokasi pengguna, proses pencarian rute terdekat dari posisi pengguna ke lokasi tujuan, proses untuk menampilkan rute dalam tampilan peta dua dimensi, dan proses untuk menampilkan rute dalam tampilan Augmented Reality. Proses di atas akan dilakukan pada sisi aplikasi berbasis perangkat bergerak. Sedangkan untuk proses pada aplikasi berbasis web adalah melakukan manajemen data lokasi yang dibutuhkan oleh aplikasi berbasis perangkat bergerak yang berisi nama lokasi dan koordinat lokasi dan menyediakan API agar aplikasi berbasis perangkat bergerak dapat mengakses data tersebut.

Pada perancangan alur penggunaan aplikasi dijelaskan alur penggunaan aplikasi yang akan dilakukan oleh pengguna. Pada Rancangan alur penggunaan ini digunakan sebagai acuan untuk membuat antarmuka dari aplikasi. Alur penggunaan aplikasi dapat dilihat pada Gambar 3.

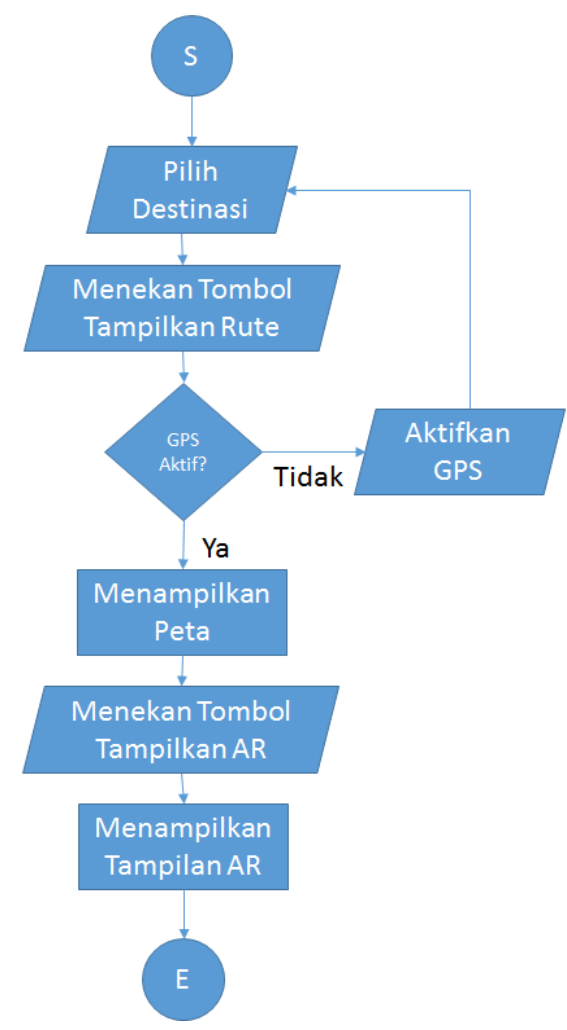

Gambar. 3. Rancangan Alur Penggunaan Aplikasi.

\section{E. Implementasi Sistem}

Pada implementasi sistem ini, dibangunlah aplikasi berbasis perangkat bergerak NavITS dan aplikasi berbasis web berupa webservice. Webservice dibangun dengan bahasa pemrograman PHP dan menggunakan kerangka kerja Code Igniter. Adapun database yang digunakan adalah database MySQL. Webservice ditempatkan pada server shared hosting agar dapat diakses melalui internet atau http request. Dibuat API untuk mengambil data lokasi dari webservice dengan melakukan http request dengan format sebagai berikut "http://navits.travis-apps.com/index.php/services." Return value dari API ini berupa string dengan format JSON yang berisi id, nama, latitude, dan longitude dari lokasi yang ada di ITS.

Aplikasi NavITS dibangun dengan bahasa pemrograman Java dengan menggunakan Android Studio sebagai IDE, Wikitude SDK untuk menangani proses visualisasi secara Augmented Reality, dan Google Maps API untuk mencari rute terdekat antara dua tempat. Antarmuka yang dibangun antara lain adalah halaman pilih destinasi yang berisi daftar lokasi yang ada di ITS, halaman peta untuk menampilkan rute dalam tampilan pera dua dimensi, dan halaman Augmented Reality untuk menampilkan rute dalam tampilan Augmented Reality. Halaman pilih destinasi dan halaman peta dapat dilihat pada Gambar 4, sedangkan halaman Augmented Reality dapat dilihat pada Gambar 5.

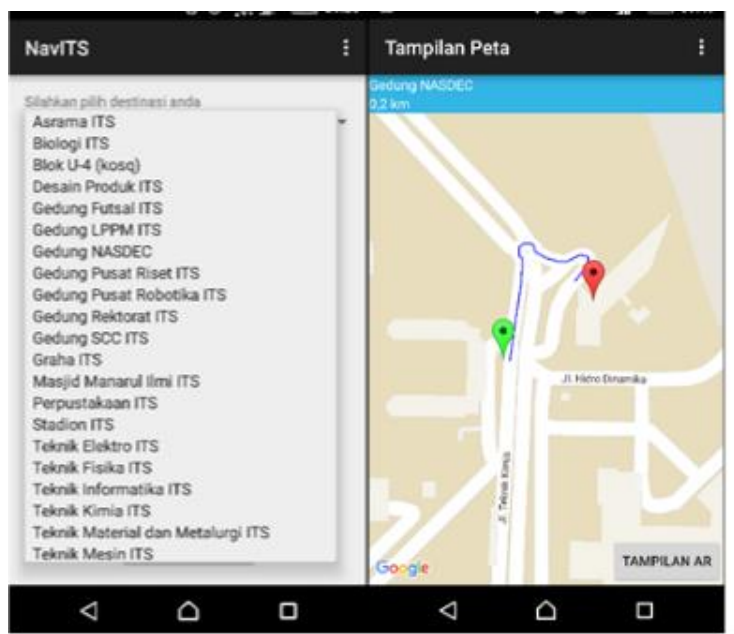

Gambar. 4. Halaman Pilih Destiansi dan Halaman Peta.

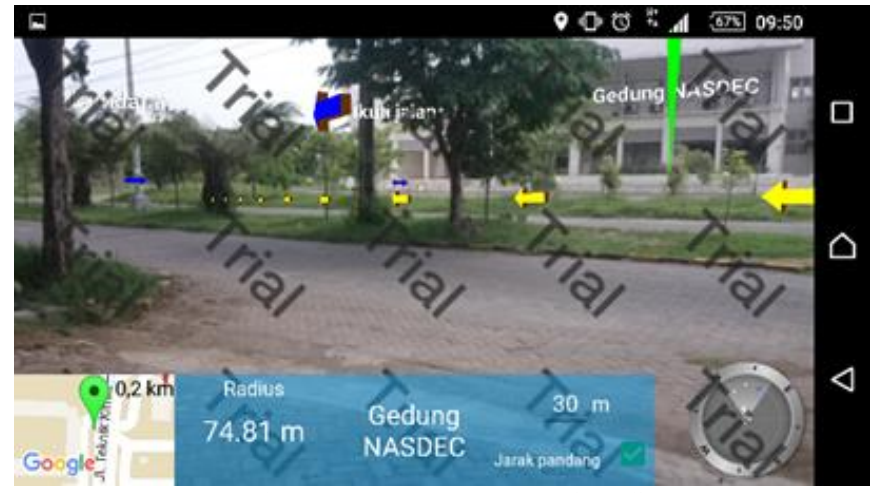

Gambar. 5. Halaman Augmented Reality. 


\section{PENGUJIAN TERHADAP PENGGUNA}

Setelah aplikasi selesai dibangun, maka perlu diuji tingkat kemudahan penggunaan dan tingkat kegunaan aplikasi ini oleh pengguna secara langsung. Pengguna yang dimaksud di sini adalah lima responden yang sudah melakukan pengujian. Responden diminta untuk menuju suatu lokasi yang ada di ITS dengan bantuan aplikasi ini, setelah itu responden diminta untuk mengisi kuesioner. Kuesioner tersebut berisi tiga pertanyaan yang memiliki bobot penilaian sebagai berikut :
1. sangat setuju $\quad=4$,
2. setuju $=3$,
3. tidak setuju $=2$,
4. sangat tidak setuju $=1$.

Berdasarkan rangkuman hasil kuesioner pengguna, dapat diketahui nilai rata-rata adalah 3,467. Nilai tersebut sudah melebihi angka 3 yang berarti "Setuju." Sehingga dapat disimpulkan bahwa aplikasi yang dibangun sudah nyaman, mudah untuk digunakan, dan membantu pengguna untuk menemukan lokasi yang ada di ITS. Rangkuman hasil kuesioner dapat dilihat pada Tabel 1.

Tabel. 1. Rangkuman Hasil Kuesioner

\begin{tabular}{|l|l|l|}
\hline No & Atribut & Nilai \\
\hline 1 & Apakah aplikasi mudah digunakan? & 3,4 \\
\hline 2 & $\begin{array}{l}\text { Apakah tampilan aplikasi nyaman untuk } \\
\text { digunakan? }\end{array}$ & 3,2 \\
\hline 3 & $\begin{array}{l}\text { Apakah aplikasi lebih membantu untuk } \\
\text { menemukan tempat yang ada di ITS } \\
\text { daripada penanda jalan maupun aplikasi } \\
\text { maps? }\end{array}$ & 3,8 \\
\hline \multicolumn{2}{|c|}{ Rata-rata nilai } & 3,467 \\
\hline
\end{tabular}

\section{KESIMPULAN/RINGKASAN}

Aplikasi NavITS yang dibangun dapat menampilkan daftar lokasi yang ada di ITS dan menampilkan rute terdekat menuju lokasi tersebut dalam tampilan peta dua dimensi dan tampilan Augmented Reality. Dari hasil pengujian pengguna, dapat disimpulkan aplikasi ini sudah nyaman dan mudah untuk digunakan dan juga dapat menjadi solusi untuk permasalahan diangkat.

\section{UCAPAN TERIMA KASIH}

Penulis I.A.F. mengucapkan terima kasih Jurusan Teknik Informatika Institut Teknologi Sepuluh Nopember, Direktorat Pendidikan Tinggi, Departemen Pendidikan dan Kebudayaan Republik Indonesia yang telah memfasilitasi penelitian ini.

\section{DAFTAR PUSTAKA}

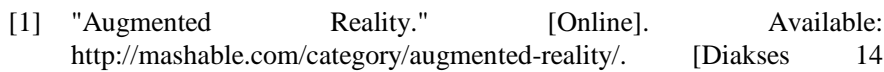
Desember 2015].

[2] Stefan Steiniger, Moritz Neun and Alistair Edwardes, "Foundations of Location Based Services", [Online]. Available: http://www.spatial.cs.umn.edu/Courses/Fall11/8715/papers/IM7_steinig er.pdf. [Diakses 14 Desember 2015].
[3] "Android Studio Overview." [Online]. Available: http://developer.android.com/tools/studio/index.html/. [Diakses 14 Desember 2015].

[4] Official U.S. Government, "What is GPS?." [Online]. Available: http://www.gps.gov/systems/gps/. [Diakses 14 Desember 2015].

[5] "Google Maps API." [Online]. Available: https://developers.google.com/maps/. [Diakses 14 Desember 2015].

[6] "Wikitude Products." [Online]. Available: http://www.wikitude.com/products/wikitude-sdk/. [Diakses 14 Desember 2015].

[7] "Profil ITS." [Online]. Available: https://www.its.ac.id/article/profilits/id. [Diakses 14 Desember 2015]. 